Н.Э. БОЙКОВА, К.М.Н., Т.И. ГАРАЩЕНКО, Д.М.Н., прОфеССОр

Научно-клинический центр оториноларингологии ФМБА России, Москва

\title{
ИРРИГАЦИОННАЯ ТЕРАПИЯ
}

\section{У ДЕТЕЙ МЛАДШЕГО ВОЗРАСТА}

\begin{abstract}
Носовое дыхание для новорожденных и детей первых лет жизни - важнейшая функция организма. Прежде всего, это возможность дышать во время кормления, что, безусловно, приоритетно в период грудного вскармливания. Кроме того, воздух, проходя через нос, согревается, увлажняется и очищается [4].
\end{abstract}

Ключевые слова: дети, затрудненное носовое дыхание, очищение полости носа.

N.E. BOIKOVA, PhD in Medicine, T.I. GARASCHENKO, MD, Prof.

Research and Clinical Center of Otorhinolaryngology FMBA of Russia, Moscow

IRRIGATION THERAPY IN YOUNG CHILDREN

Nasal breathing for newborns and infants is the most important function of the body. First of all, good breathing allows to breathe during feeding, which is certainly a priority during the breastfeeding period. In addition, when passing through the nose, the air gets warm, humidified and clean.

Keywords: children, shortness of nasal breathing, nasal irrigation.

осовые ходы у младенцев очень узкие, а носовые раковины относительно толстые, поэтому даже незначительное скопление слизи вызывает затруднение дыхания. Верхний носовой ход отсутствует, средний и нижний - развиты слабо. Нижняя носовая раковина касается дна полости носа. Носовые раковины не достигают перегородки полости носа, общий носовой ход остается свободным, и через него осуществляется дыхание новорожденного, хоаны низкие. К 6 месяцам жизни высота полости носа увеличивается до 22 мм и формируется средний носовой ход, к 2 годам - нижний, после 2 лет - верхний.

Слизистая оболочка новорожденного очень нежная и обильно снабжена кровеносными сосудами, а вот пещеристая ткань под ней, которая отвечает в том числе за согревание поступающего через нос воздуха, развита слабо.

Околоносовые пазухи у малышей развиты очень слабо (верхнечелюстная пазуха и решетчатый лабиринт) или вообще отсутствуют (верхнечелюстные и лобные пазухи), поэтому гайморит и фронтит им не грозят, чему нельзя не порадоваться.

Евстахиева труба, соединяющая носоглотку со средним ухом, у грудничка намного прямее и короче, чем у взрослого или у ребенка старшего возраста, и проходит в одной плоскости с глоткой. А поскольку малыш почти постоянно находится в горизонтальном положении, слизь из носоглотки, вместе с содержащимися в ней болезнетворными микроорганизмами, легко попадает в уши. Именно поэтому отиты у малышей - не редкость.

Носослезный проток младенцев широкий, клапаны, перекрывающие его, недоразвиты, поэтому любое воспаление быстро «перекидывается» на слизистую оболочку глаз [10].

Новорожденные и дети первых лет жизни не способны самостоятельно очищать полость носа от отделяемого, как от жидкого, так и густого (корки), что часто встречается при недостаточной влажности воздуха в помещении.
Bсе это затрудняет носовое дыхание, провоцируя инфицирование полости носа (острые риниты) и его дальнейшее распространение в носоглотку и полость среднего уха. Нарушение носового дыхания служит причиной нарушения качества жизни у новорожденных и грудных детей. Нарушается акт сосания и глотания, малыш может отказываться от еды, медленнее набирать вес. Проблемы с носовым дыханием могут даже привести к повышению внутричерепного давления и расстройству функции центральной нервной системы $[4,5,9]$. Дети первых лет жизни становятся беспокойными, капризными, у некоторых малышей отмечается нарушение сна. Длительное затруднение носового дыхания приводит к гипоксии, способствует замедлению умственного и физического развития ребенка.

Дети с нарушенным носовым дыханием начинают дышать ртом, поступающий при этом в дыхательные пути холодный воздух легко приводит к простудным заболеваниям, такие дети чаще болеют.

Такое явление, как срыгивание, характерное для новорожденных и грудных детей, способствует раздражению слизистой оболочки носа и носоглотки желудочным содержимым и воспалению - риниту, который проявляется длительным затруднением носового дыхания.

Таким образом, очищение полости носа - естественный процесс для любого взрослого человека (высмаркивание) - недоступен для малышей. Это значит, что время от времени необходимо увлажнять полость носа при помощи специальных детских капель, а именно стерильного изотонического солевого раствора, и удалять слизь и корочки при помощи аспиратора. Подобные средства всегда должны быть в домашней аптечке.

При закапывании капель ребенку в нос необходимо повернуть голову набок. Через несколько секунд малыша следует поднять «столбиком», чтобы жидкость распределилась внутри носа. Удаляют размягченную слизь ватными турундочками, то есть плотными жгутиками, скрученными вручную. Ватные палочки для обработки носика 
использовать нежелательно: ими можно повредить нежнейшие внутренние покровы.

Точный возраст, когда малыш «должен» научиться сморкаться, назвать невозможно, но начинать можно в любой момент, когда ребенок уже хорошо понимает обращенную к нему речь и готов следовать несложным инструкциям.

Задача проста - научить малыша дуть носом. Чтобы увлечь ею ребенка, надо сделать процесс наглядным задуть носиком свечку, сдуть кусочек ватки или бумажной салфетки, создавать «туман» на зеркале.

Для упражнений лучше выбрать время, когда нос дышит свободно. Такая предусмотрительность рано или поздно даст хороший результат. Сначала делаем как проще - дуем ртом, а потом пытаемся повторить то же самое носом. Еще можно поиграть в ежика или в паровозик. Ребенку гораздо веселее будет не просто сморкаться по команде, а с удовольствием показывать маме «как говорит ежик» или «как пыхтит паровоз». При азартности малыша можно устроить соревнование - у кого дальше улетит фантик от конфеты или быстрее погаснет свеча. Но этим приемом не стоит злоупотреблять, поскольку, увлекшись, ребенок может начать дуть слишком сильно.

Все эти упражнения лучше сразу проделывать поочередно обеими ноздрями, потому что эффективное и безопасное высмаркивание осуществляется именно так: одну ноздрю прижимаем пальцем к носовой перегородке, другую освобождаем от всего лишнего.

Ни в коем случае не учите ребенка дуть носом «изо всех сил» - так можно запросто «надуть» себе отит, поскольку повышенное давление направляет слизь вместе с болезнетворными микробами совсем не туда, куда нужно, а в евстахиеву трубу.

Проблемы могут возникать и из-за густоты выделений - и взрослому человеку порой трудно освободиться от подсохшей или вязкой слизи. Лучшие «помощники» в такой ситуации - препараты, содержащие физиологический раствор, благодаря которым выделения разжижают-

\section{Таблица 1. Рекомендации по лечению острого риносинусита у детей [5]}

\begin{tabular}{|c|c|c|c|}
\hline Терапия & 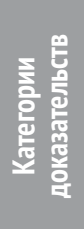 & 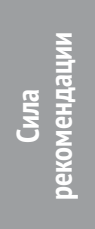 & 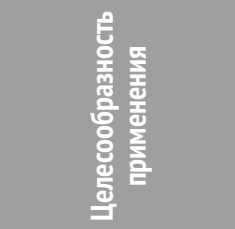 \\
\hline Антибиотик внутрь & $\mathrm{Ia}$ & A & $\begin{array}{c}\text { Да, при сохранении } \\
\text { симптомов более } \\
5 \text { дней или в } \\
\text { тяжелых случаях }\end{array}$ \\
\hline Стероиды местно & IY & D & Да \\
\hline $\begin{array}{l}\text { Стероиды местно в сочетании } \\
\text { с антибиотиками внутрь }\end{array}$ & $\mathrm{lb}$ & A & Да \\
\hline Местно деконгестант & III(-) & C & Нет \\
\hline Промывание полости носа & IY & D & Да \\
\hline
\end{tabular}

ся и отходят намного легче. Повернув голову ребенка набок, следует закапать солевой раствор в «верхнюю» ноздрю, а через несколько секунд предложить высморкаться или использовать аспиратор. А также не забываем об увлажнении воздуха и обильном питье!

Важным направлением является элиминационная терапия, направленная на превентивное активное снижение вирусных и бактериальных патогенов на слизистых дыхательных путей в эпидемически опасные периоды. Ее использование разжижает слизь, способствует ее легкому удалению, уменьшает заложенность носа и воспаление слизистой, устраняет зуд, чихание, боль в полости носа [2, 3, 7].

\section{Основные направления элиминационной терапии}

1. Профилактика ОРВИ и гриппа в период эпидемий

2. Комплексное лечение риносинуситов, в том числе у новорожденных

3. Увеличенные аденоиды и их воспаление

4. Атрофические риниты и их профилактика

5. Послеоперационный уход

6. Аллергические риниты

7. Комплексное лечение фарингитов и ларинготрахеитов

8. Уход за полостью носа у новорожденных и грудных детей увлажняет слизистую полости носа

Использование элиминационной терапии - неотъемлемая часть лечения риносинуситов у детей, что находит отражение в клинических рекомендациях, а также многочисленных исследованиях (табл. 1, 2) [2, 3, 5, 7, 8].

Важной частью терапии аллергического ринита у детей является элиминационная терапия, которая позволяет устранить аллергены (Рекомендации и алгоритмы при детском аллергическом рините (РАДАР) 2015), ускоряет ослабление симптомов аллергического ринита, значительно уменьшает потребление базовых препаратов (системные антигистаминные препараты, топические глюкокортикостероиды (ТГКС), сосудосуживающие средства) и уменьшает побочные эффекты от приема ТГКС (табл. 3) [1].

У детей младшего возраста проведение элиминационной терапии целесообразно препаратом Отривин Бэби.

\section{Таблица 2. Эффективность элиминационной терапии при остром риносинусите и аденоидите у детей [3]}

\begin{tabular}{|c|c|c|c|}
\hline Показатели & 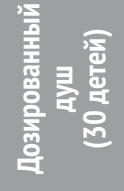 &  & 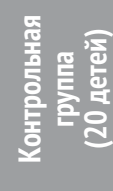 \\
\hline Уменьшение отечности ГМ* & $21(70 \%)$ & $15(77 \%)$ & $11(55 \%)$ \\
\hline $\begin{array}{l}\text { Нормализация цвета слизистой } \\
\text { оболочки ГМ* }\end{array}$ & $25(83 \%)$ & $16(78 \%)$ & $14(70 \%)$ \\
\hline $\begin{array}{l}\text { Отсутствие отделяемого } \\
\text { на поверхности ГМ* }\end{array}$ & $26(87 \%)$ & $18(90 \%)$ & $9(45 \%)$ \\
\hline Отсутствие рефлюкса в ГУСТ & $27(90 \%)$ & 19 (95\%) & $10(50 \%)$ \\
\hline $\begin{array}{l}\text { Среднее количество пункций } \\
\text { верхнечелюстных пазух }\end{array}$ & 1,7 & 1,6 & 2,4 \\
\hline
\end{tabular}




\section{Таблица 3. Ступенчатая терапия аллергических ринитов у детей}

\begin{tabular}{c|c|c}
\hline 1 ступень & 2 ступень & 3 ступень \\
\hline Легкая форма & Среднетяжелая форма & Тяжелая форма \\
\hline & $\begin{array}{c}\text { Специфическая } \\
\text { иммунотерапия } \\
\text { аллергенами (СИТ) }\end{array}$ & $\begin{array}{c}\text { Специфическая } \\
\text { иммунотерапия } \\
\text { аллергенами }\end{array}$ \\
\hline Кромоны & $\begin{array}{c}\text { Кромоны или } \\
\text { топические стероиды }\end{array}$ & Топические стероиды \\
\hline $\begin{array}{c}\text { Топические } \\
\text { антигистаминные } \\
\text { препараты }\end{array}$ & $\begin{array}{c}\text { Топические } \\
\text { или системные } \\
\text { антигистаминные } \\
\text { препараты }\end{array}$ & $\begin{array}{c}\text { антигистаминные } \\
\text { препараты }\end{array}$ \\
\hline
\end{tabular}

Топические сосудосуживающие препараты (короткий курс)

Элиминация причинно-значимых аллергенов и провоцирующих факторов

Капли для детей Отривин Бэби предназначены для мягкого орошения слизистой оболочки носа у детей с рождения, помогают увлажнить полость носа при сухости и раздражении в условиях сухого воздуха при работе нагревательных приборов или кондиционирования воздуха в помещении и подходят для ежедневной гигиены полости носа малышей. Отривин Бэби при регулярном использовании увеличивают способность слизистой бороться с бактериями и вирусами, а также помогают избежать простудных и аллергических заболеваний.

В состав средств медицинского назначения Отривин Бэби входят:

- Аспиратор

- Сменные насадки

- Капли для орошения полости носа (18 x 5 мл)

- Спрей для орошения полости носа (20 мл)

В его составе стерильный изотонический раствор хлорида натрия 0,74\%, уровень рН которого близок к назальному секрету, натрия гидрофосфат, натрия фосфат, макрогола глицерилрицинолеат и очищенная вода. Препарат создан без консервантов и не вызывает аллергии. Стерильный изотонический солевой раствор идеально подходит для лечения и ухода за полостью носа, особенно младенцам и детям до 2 лет.

\section{Как же грамотно использовать Отривин Бэби? Шаг 1 - закапываем раствор}

- Воспользуемся солевым раствором Отривин Бэби, чтобы промыть ребенку нос. Для этого достаточно закапать несколько капель в каждый носовой ход.

口 Процедура выполняется, когда малыш лежит. Если мы капаем раствор в правую ноздрю, то слегка поворачиваем голову ребенка влево, и, наоборот, если капаем в левую, то поворачиваем голову вправо. Промывание носика делается для того, чтобы размягчить носовую слизь и после легко ее удалить, а также, чтобы увлажнить полость носа. Все это существенно облегчит состояние крохи.
Следует пользоваться открытым флаконом в течение 12 ч. Для новорожденных идеально подходят капли в одноразовых флаконах.

- Для малышей с 3 месяцев разрешено также использовать Отривин Бэби спрей с удобным дозатором.

\section{Шаг 2 - отсасываем аспиратором}

Просто и удобно очистить нос от выделений поможет аспиратор Отривин Бэби. Сначала необходимо соединить аспиратор с одноразовой насадкой. Защиту малыша и мамы от инфекции во время выполнения процедуры обеспечит пенообразный фильтр, который есть в каждой насадке. - Итак, первым делом подносим мундштук аспиратора к своим губам. После этого вставляем кончик аспиратора в носик малыша и осторожно втягиваем воздух через мундштук. Благодаря прозрачным стенкам насадки можно легко проконтролировать, сколько слизи удалилось. Теперь делаем все то же самое, вставив кончик аспиратора в другой носовой ход ребенка.

- Когда процедура окончена, то устройство не нужно промывать и дезинфицировать. Нужно выбросить одноразовую насадку с фильтром, а в следующий раз использовать новую.

\section{Достоинствами ирригационной терапии являются:}

Снижение носового сопротивления и улучшение носового дыхания;

—лучшение функции мерцательного эпителия;

- Улучшение пассажа слизи;

Уменьшение отека слизистой, улучшение дренажа через естественные соустья;

- Элиминация аллергенов в целях профилактики аллергического воспаления;

- Снижение концентрации провоспалительных медиаторов в назальном секрете при аллергии;

- Элиминация патогенов в целях профилактики ОРВИ и бактериальной инфекции.

Приведем примеры ситуаций, при которых требуется различный подход к назначению топической интраназальной терапии.

Назальная обструкция («нос не дышит»)

Это означает, что слизистая сильно отекла и, чтобы восстановить носовое дыхание, необходимо снять отек. Все знают, что самый простой способ сделать это - закапать сосудосуживающие капли. Эффект моментальный и держится какое-то время. Однако применять подобные средства нужно с большой осторожностью:

1) форма выпуска препарата и концентрация действующего вещества должны соответствовать возрасту, взрослые капли детям не подходят (Отривин детский, Виброцил $\left.{ }^{\circledR}\right)$;

2) продолжительность и частоту применения необходимо согласовывать с врачом, так как сосудосуживающие препараты при неправильном использовании вызывают привыкание и «отучают» слизистую справляться с проблемой самостоятельно, а также нарушают ее питание.

\section{Обильное водянистое отделяемое}

- Первая стадия инфекционного ринита (ОРВИ). Если обильные выделения продолжаются более 5 суток, необходима дифференциальная диагностика с аллергическим ринитом (использование антигистаминных системных и топических препаратов - Фенистил ${ }^{\circledR}$, Виброцил $\left.{ }^{\circledR}\right)$. 


\section{Отрuвuн}

\section{БэБU}

Позвольте носу дышать

Удобный и современный способ ухода за носиком малыша:

- при простудных заболеваниях

- для ежедневной гигиены

- при аллергии

\section{Применение комплекса Отривин Бэби}
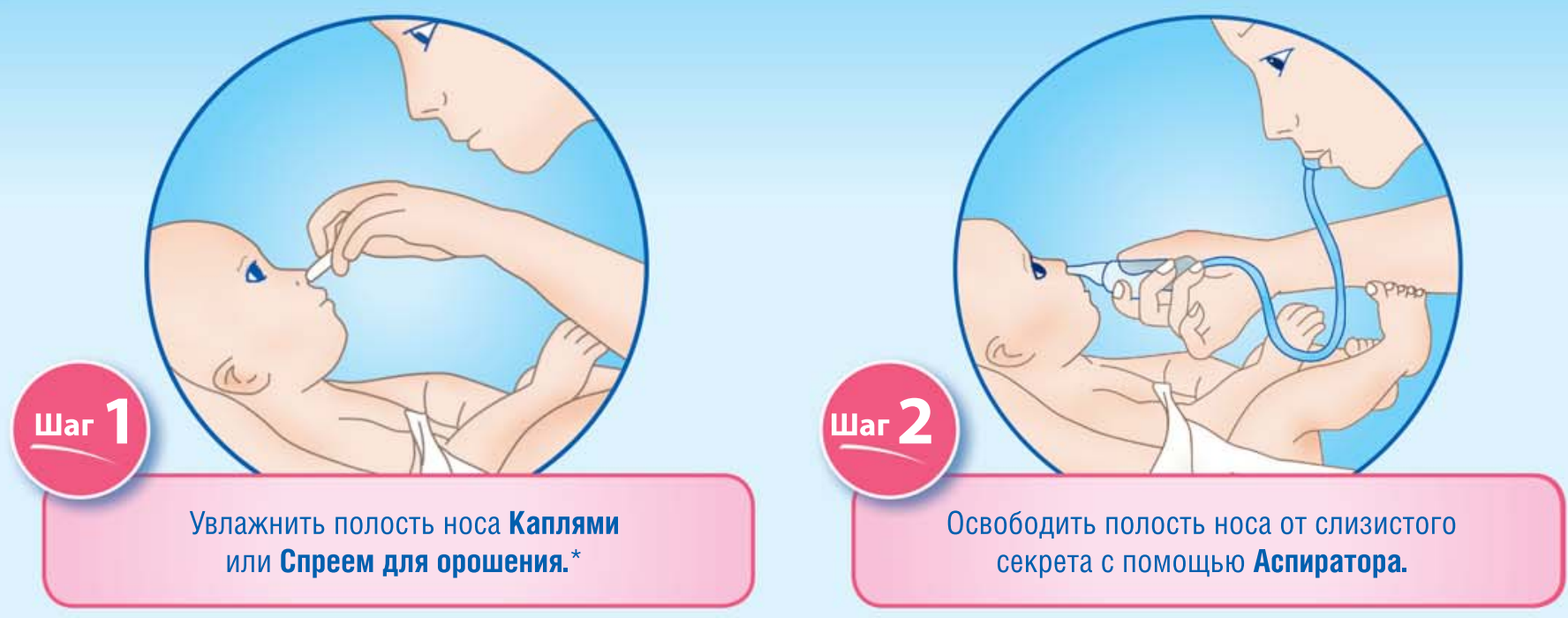

Комплекс Отривин Бэби предназначен для новорожденных, грудных детей и детей младшего возраста

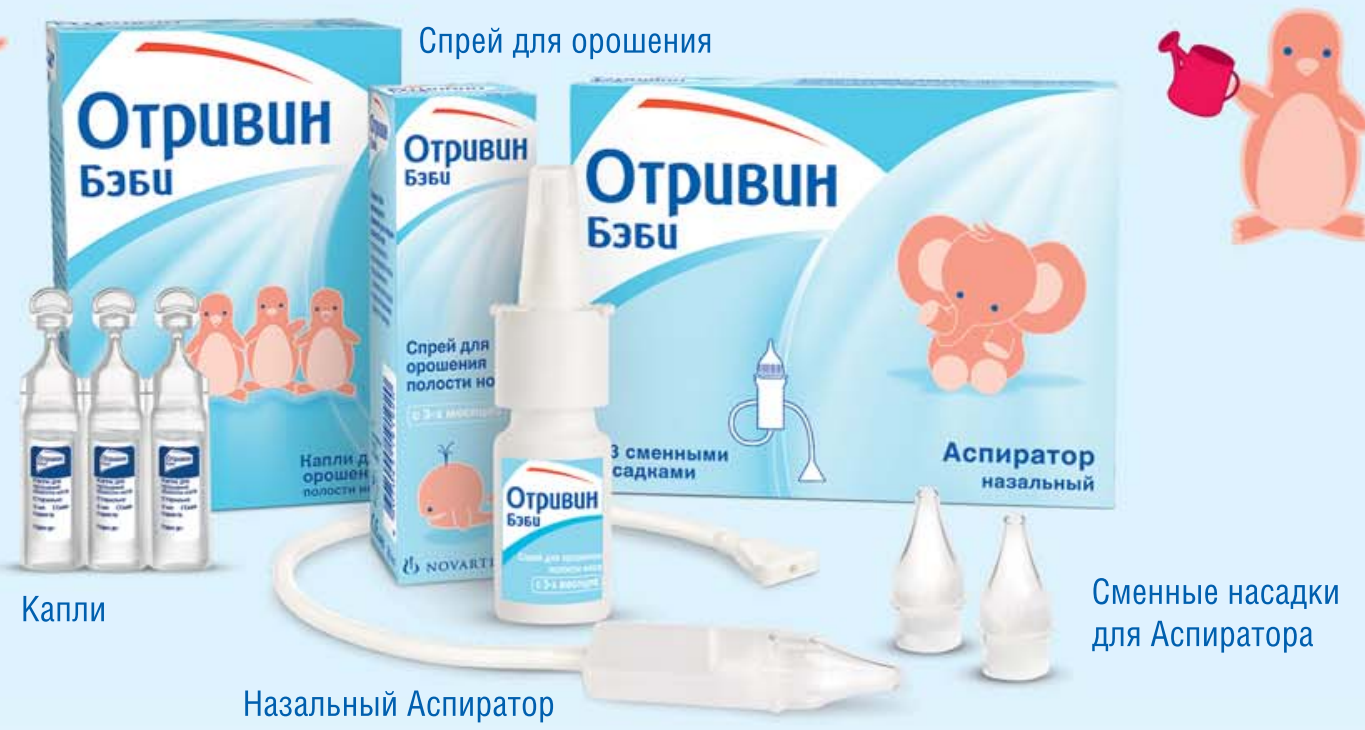

*Спрей с 3 месяцев.

123112. Россия, Москва, Пресненская наб., д. 10. Тел.: 8 (495) 777-98-50 


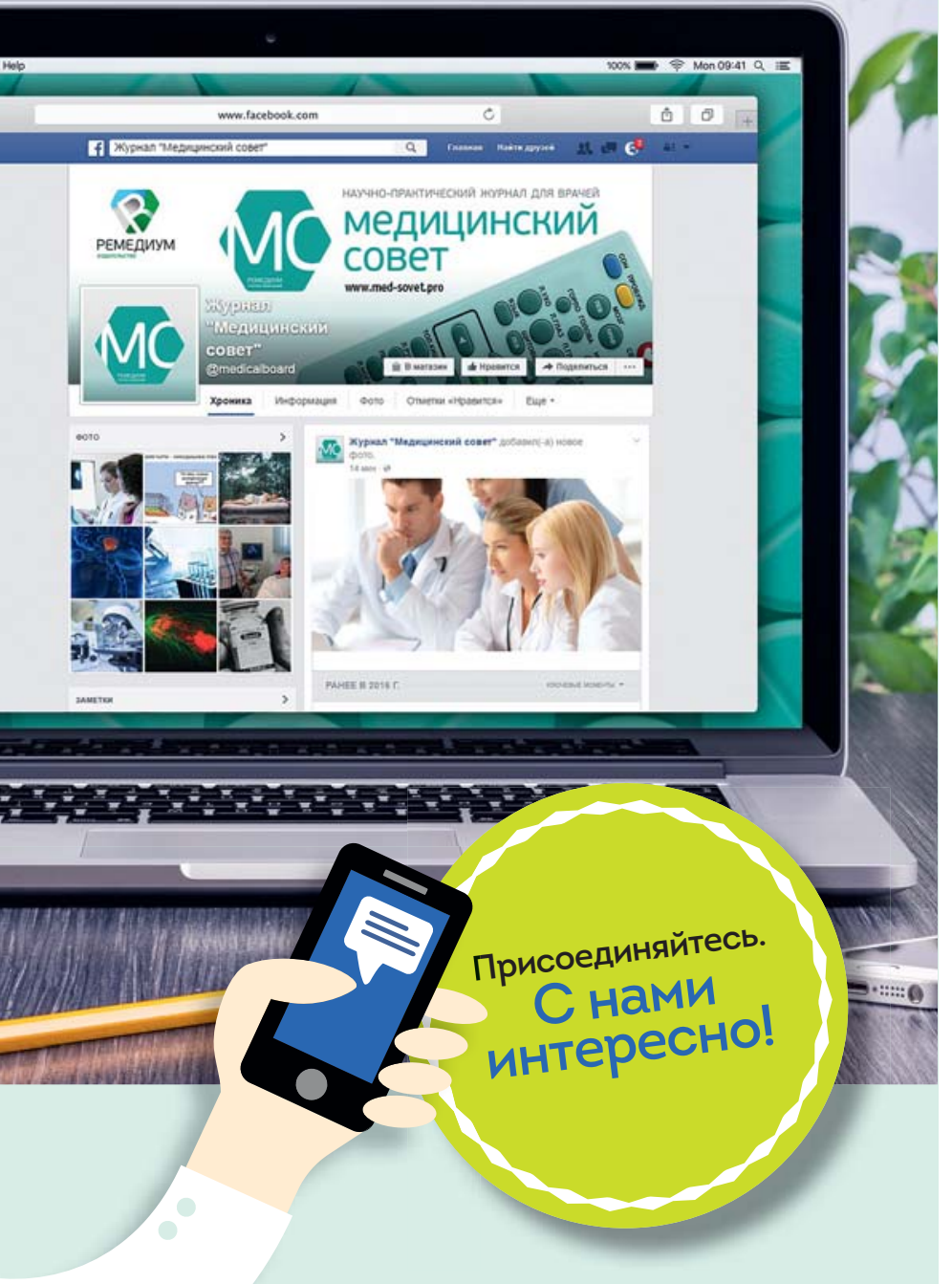

В остальных случаях достаточно минимизировать раздражение кожи, возникающее при частом высмаркивании: используйте как можно более мягкие носовые платки.

\section{Густое отделяемое («корки»)}

- Слизь загустела, плохо отходит, мешает дышать, вызывает кашель. Самое главное здесь - увлажнение «по всем фронтам»: обильное питье, увлажнители воздуха, солевые растворы в нос с последующим высмаркиванием или применением аспиратора, если ребенок еще не умеет избавляться от выделений в носу самостоятельно (Отривин море, Вибролор, Отривин Бэби).

\section{Густое отделяемое в носоглотке}

- Густая слизь в носоглотке - идеальная среда для размножения бактерий. Поэтому для предотвращения бактериальных осложнений после обычного ОРВИ вы должны сделать все, чтобы она стала более жидкой и легкоотделяемой. Это важно еще и потому, что чрезмерные усилия, прилагаемые при высмаркивании густой слизи, увеличивают риск возникновения отита.

Таким образом, Отривин Бэби - средство для элиминационно-ирригационной терапии, рекомендуется для широкого использования в домашних условиях с целью ежедневной гигиены полости носа и ухода за полостью носа малышей, страдающих острыми ринитами, риносинуситами и аллергическими ринитами.

\section{$\mathrm{MC}$}

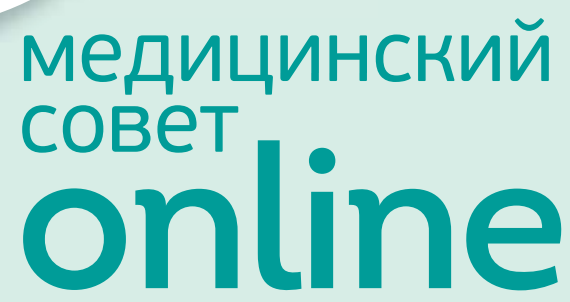

- актуальные новости о разных разделах медицины

- интересные события и открытия в России и в мире

- анонсы журнала "Медицинский совет»

- инфографика

- заметки в помощь практикующим врачам

- история науки и медицины

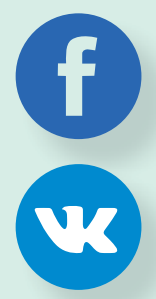

Наша группа в «Фейсбуке» facebook.com/medicalboard vk.com/med_sovetpro 